\title{
Design on Logistics Information Management System for Large Sports Events
}

\author{
Li Li \\ Logistics Business College, Hunan Vocational College of Modern Logistics, Changsha, 410131, China
}

250491594@qq.com

Keywords: Large sports events, Logistics information management, System design, Function design, Technical framework; Data access.

\begin{abstract}
With the rapid development of modern science and technology, the trend of globalization of modern sports has been strengthened; the scale of sports competition is growing. Logistics as an important part of sports management and service, is the basis for the successful holding of the event, and more and more attention by the organizers. The development of logistics information system for large sporting events provides the full range of logistics information services. Based on the idea and method of software engineering, this system design is based on the basic theory, content and characteristics of large sports event logistics. The system function design, technical frame design and data access design are designed to provide solutions for system development. The successful application of this system is of great significance to improve the management level of the tournament, reduces the logistics cost and improves the marketization degree.
\end{abstract}

\section{Introduction}

Large sports event logistics refers to meet the needs of large sports events such as the Olympic Games, the Asian Games, the World Cup and the National Games, and the material circulation process from the supply of goods to the venue of the event and its extension service. Mainly related to the transport of goods, handling, handling, storage and specific distribution and other links, and in accordance with the requirements of the parties to provide a variety of extension and value-added services. Large-scale sports events on the demand for logistics services in the short term "outbreak", held during the high demand for logistics services, held a gap on the logistics service demand is low, the logistics flow service content has great uncertainty, logistics services are facing greater The challenge. Therefore, the development of large-scale sports event logistics information system for large-scale sports events to provide a full range of logistics information services, to improve the management level of the event, reduce logistics costs, improve the degree of marketization is of great significance.

\section{Logistics Foundation on Large Sports Events}

Large sports events logistics foundation includes three aspects: theory, content and characteristics.

(1) Large sports event logistics theory[1]. The theory of large-scale sports events logistics should include basic theory, applied theory and development theory.

$>$ Basic theory. Based on the general theory of the large sports events logistics and practical activities of the general summary and summary of the overall perspective of the large sports events in the general sense of the inquiry, including two basic components of the concept and basic method, and have comprehensive, versatility and frontier characteristics and so on.

$>$ Application theory, from the logistics management layer, logistics technology application layer and logistics engineering layer, the sports event logistics special activities study, undertake the major sports events logistics basic theory and make it specific refinement. Management theory, technical theory and engineering theory, together constitute the large 
sports events logistics application theory.

$>$ Development theory, from the perspective of long-term and future, put forward the sporting event logistics planning and design of the prospective recommendations and planning, rooted in the basic theory of sports logistics and application theory, with a higher level of sports logistics theory, for sporting events, the development of logistics is predictive and forward-looking.

(2) Large sports events logistics content[2]. Based on the analysis of the service object and operation process of the large sports event logistics, the contents of the logistics are summarized as follows:

$>$ Equipment logistics, large sports events involved in lots of projects, a variety of specifications, varieties and sizes of special equipment geographical distribution of scattered, need to focus in a short time. From the cost control point of view, some of the equipment versatility, according to the game time difference, timely dismantling for other events.

$>$ Supporting logistics. Mainly refers to the audience and staff of the transportation, catering and raw materials procurement processing, office supplies and other logistical support logistics activities. The level of these services is directly related to the public satisfaction and evaluation of the event.

> Accessories logistics. Including the mascot, clothes, game supplies, pictures, stamps, souvenirs, etc., the transport of these ancillary goods, processing and distribution activities, the need for a short period of time to complete the product transshipment, processing and distribution services, in time to meet the distribution needs of the distribution points The

$>$ Reverse logistics. It is the core of the logistics services to expand, its significance is not only to promote the concept of the event, more importantly, through reverse logistics, improve waste utilization, and achieve value recovery and appropriate treatment of toxic substances.

(3) The characteristics of large-scale sports events logistics[3]. Including the following four aspects:

$>$ Diversity of logistics subjects. Large sports event, lots of participating subjects, differences in the nation, customs, religion, age and so on. The diversity of demand due to participation in the diversity of the main subject is a factor that must be considered in logistics service.

$>$ Security of logistics object. Large sports events involved in the competition equipment and news equipment, as well as the staff and their life needs protection, which are key conditions, logistics service providers must ensure the safety of the logistics process.

$>$ Periodicity of logistics time. Event logistics is periodical in the time, generally can be divided into three period, including pre-match preparation period, the period of supply and post-match recovery period. Each period of the logistics service work has different focus.

$>$ Concentration of logistics space. Taking into account the time of the game and the rest of the athletes, competition venues and athletes are often relatively concentrated in the venue. The event logistics is basically between venues, athletes' residences and logistics centers.

\section{System Function Design}

Functional design methods commonly using are simulation. Modularization is an important design idea that breaks down a complex system into smaller, simpler, and easier to establish and modify parts. On the one hand, each module is relatively independent and can be designed separately , On the other hand, the relationship between the modules through a certain way to be explained. Each module under the constraints of these relations together constitute a unified whole, the completion of the system functions. The process of functional design is to decompose, constitutes the function of the relationship between the representation of the graphics. The process of functional decomposition is from abstract to concrete, from complex to simple. Through the analysis of the business of large sports event logistics information management system, based on the simulation design idea, the system function is summarized into six subsystems, each subsystem includes five modules, as shown in Fig.1. 
(1) Customer relationship subsystem. Customer relationship provide customers with satisfaction, thoughtful service, improve customer satisfaction, loyalty for the purpose of a management mode of operation. Through the comprehensive management of customer information, business and customers achieve zero distance communication.

(2) Electronic business subsystem. Electronic business logistics, also known as online logistics, is a broad prospect for the service, mainly for sporting goods end users, through a series of online behavior, logistics supply to reach a deal by each other.

(3) Job management subsystem. According to the operation process management, according to different logistics activities to control costs, business analysis, continuous improvement of the operating process, and achieve the lowest cost of logistics and operating procedures for the best.

(4) Warehouse management subsystem[4]. Achieve the classification of sports logistics products, integration and circulation processing, storage information collection, transmission, update and statistical analysis work to adjust the supply and demand, and the real-time supervision of warehousing.

(5) Decision support subsystem. Provide management layer decision supporting for sports logistics companies, including strategic, tactical or executive layer decisions. Provides a kind of systematic quantitative analysis method based on scientific methods.

(6) Maintenance management subsystem. For the system administrator to maintain the system, including the code dictionary information maintenance, user rights granted and withdrawn, data backup and recovery, log file management and system information publication.

\begin{tabular}{|c|c|c|c|}
\hline Short message service & Online evaluation & ! & Financial management \\
\hline Mail service & Online payment & & Exception handling \\
\hline Individual service & Online tracking & & Transportation management \\
\hline User audit & Online enquiry & $\mid \begin{array}{l}1 \\
1 \\
1 \\
1 \\
1\end{array}$ & Scheduling management \\
\hline User registration & Online orders & & Order management \\
\hline $\begin{array}{l}\text { Customer relationship } \\
\text { subsystem }\end{array}$ & $\begin{array}{c}\text { Electronic business } \\
\text { subsystem }\end{array}$ & ' & $\begin{array}{c}\text { Job management } \\
\text { subsystem }\end{array}$ \\
\hline \multicolumn{4}{|c|}{$\begin{array}{l}\text { Logistics Information Management System } \\
\text { for Large Sports Events }\end{array}$} \\
\hline $\begin{array}{c}\text { Warehouse management } \\
\text { subsystem }\end{array}$ & $\begin{array}{c}\text { Decision support } \\
\text { subsystem }\end{array}$ & (i) & $\begin{array}{c}\text { Maintenance management } \\
\text { subsystem }\end{array}$ \\
\hline In-warehouse management & Plan management & $\left|\begin{array}{ll}1 \\
1 \\
1 & 1 \\
1\end{array}\right|$ & Basic information \\
\hline Out-warehouse management & Forecast management & $\left.\mid \begin{array}{lll}1 & 1 \\
1 & 1 \\
1\end{array}\right]$ & User permissions \\
\hline Check management & Statistical analysis & {$\left[\begin{array}{ll}1 & 1 \\
1 & 1\end{array}\right]$} & System log \\
\hline Inventory management & Data mining & {$\left[\begin{array}{ll}1 & 1 \\
1 & 1\end{array}\right]$} & Data security \\
\hline Storage control & Business intelligence & {$\left[\begin{array}{lll}1 & 1 \\
1 & 1\end{array}\right]$} & Information publish \\
\hline
\end{tabular}

Fig. 1. Function on logistics information management system for large sports events 


\section{System Technical Framework}

B / S structure is a new type of network management information system platform model based on Web technology. The server part of the traditional two-tier C / S structure is decomposed into Web server and database server, which constitutes the three-tier structure customer server system. In essence, the client and the Web server are similar to the terminal and host modes, and the Web server and the database server are similar to the C / S mode. Large sports event logistics information management system using B / S structure, technical framework shown in Fig.2 below.

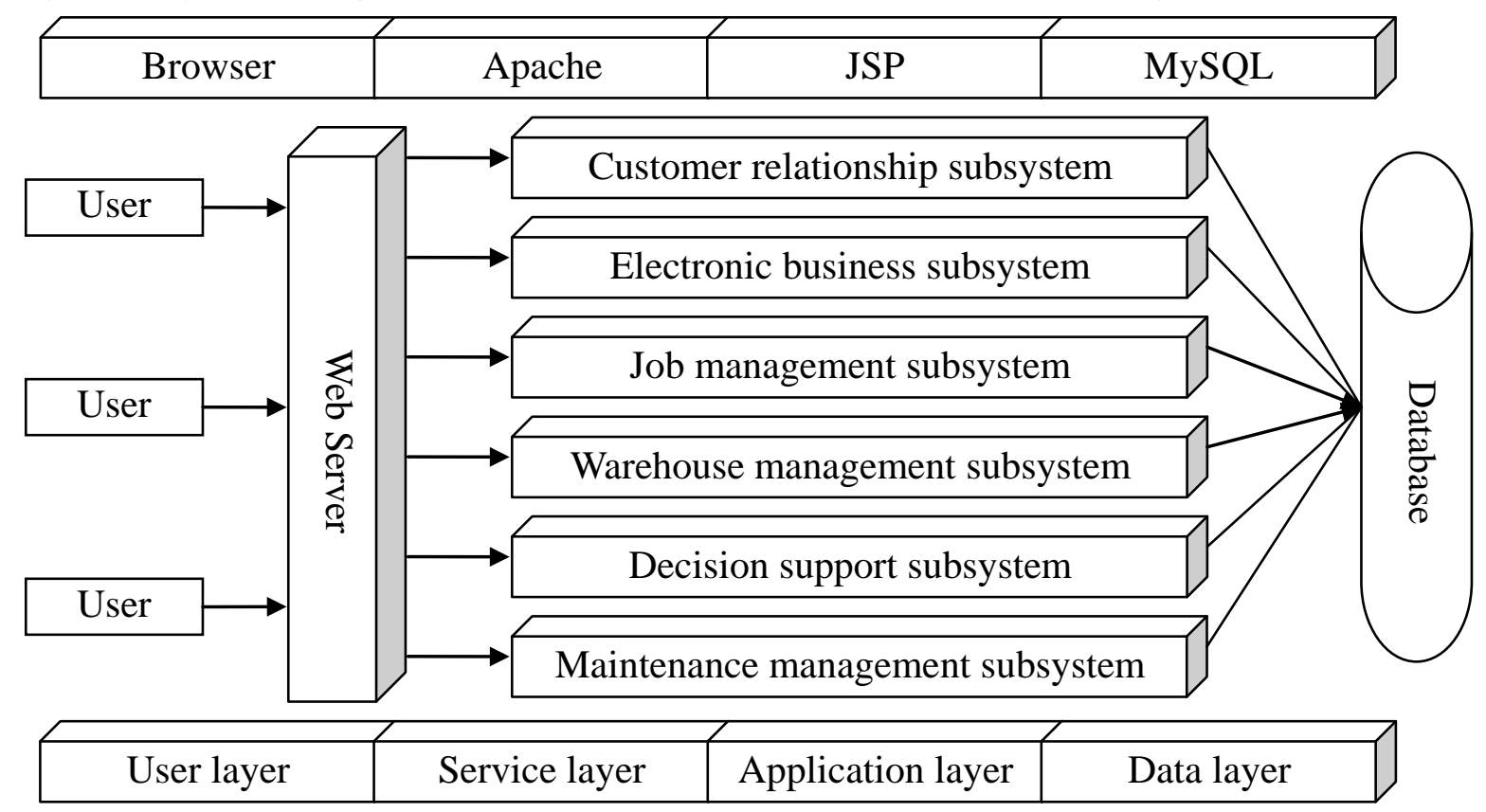

Fig. 2. Technical framework on logistics information management system for large sports events

(1) User layer[5], the application which presents data to the user or processes the user input, not the implementation of data functions, but by inputting to the server request data, and then displays the results in a certain format. Some user layers can also implement business logic, can be divided into Web-based and non-Web-based two client cases. In the case of Web-based, mainly as the corporate Web server browser, non-Web-based client layer is the independent application.

(2) Service layer, in order to establish browser-based applications, provide enterprise-class information services, the system requires Web server to store information and applications. Through the client software, provides users with a variety of services. Application services store a variety of shared information and applications, and as a gateway to access the application server for different users with different combinations of applications.

(3) Application layer, application server for the realization of specific applications. Web server provides communication between the client and the application server, which is responsible for complex business processing, the client's operation reach the Web server, according to the specific needs, into the application server to complete. Through the application server form SQL statements and data layer in the database system exchange information. For a database server, the application server is equivalent to a client.

(4) Data layer, will be from different subsystems of data information, centralized storage in the database for sorting and maintenance, for the original subsystems already exist in different types of database, you can use the data exchange platform or other data interface, and interconnection achieve different subsystems based on a variety of databases on the cross-access. 


\section{Data Access Design}

Data access is the basic work of managing the system development process. JDBC (Java Data Base Connectivity) is a Java API for the implementation of SQL statements, which can be a variety of relational database for data access methods. Spring is an open source framework, the core technology is a lightweight container for J2EE-based enterprise application development to provide a full range of support application framework[6]. Spring framework based on the development of Java applications, there are two kinds of data access methods, one is Spring JDBC, the other is Spring Hibernate, the system uses Spring JDBC. Access to the database process shown in Fig.3.

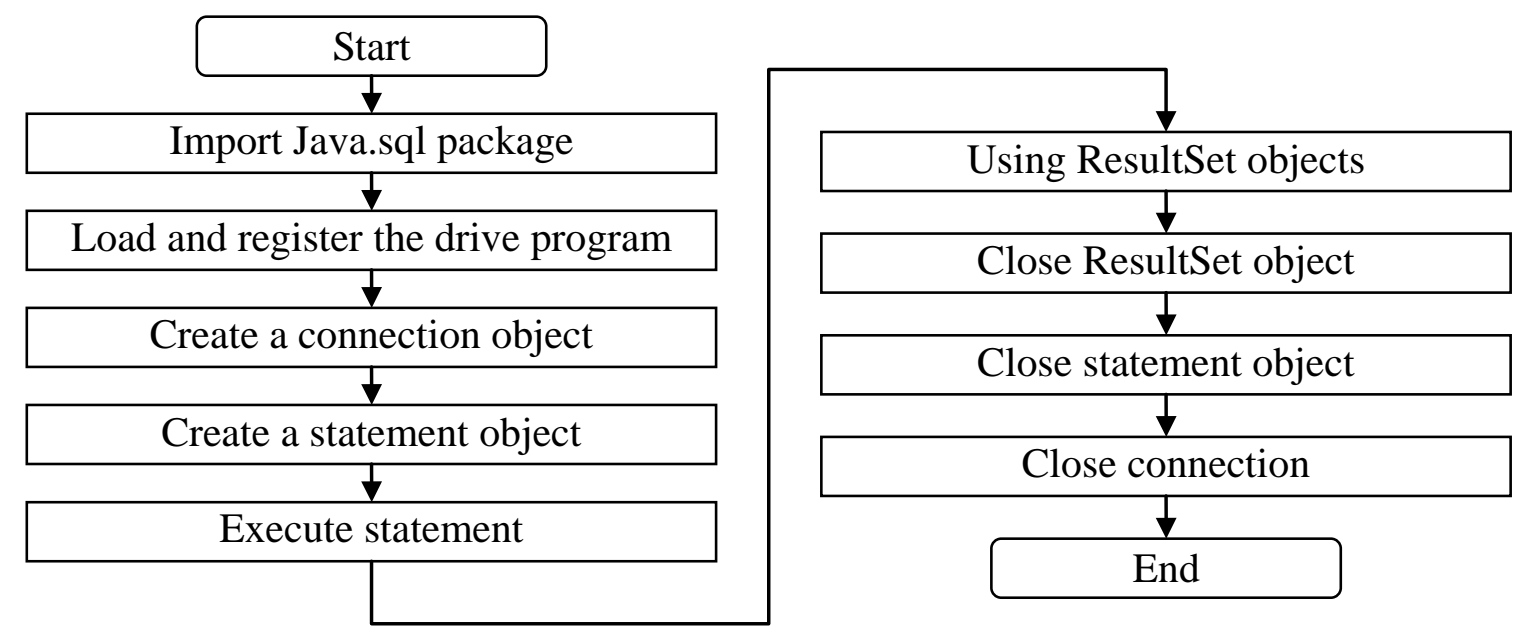

Fig. 3. JDBC Access to the Database Process

JDBC provides a benchmark, so you can build more advanced tools and interfaces, so that database developers can write database applications. JDBC is an API for Java programmers and an interface model for implementing service providers that connect to the database. As an API, JDBC provides a standard interface for program development and provides a standard way for database vendors and third-party middleware vendors to connect to the database[7]. Spring JDBC is the Spring framework for JDBC packaging, using the template design pattern. When performing various operations on the database, the repetitive code required to use JDBC directly through the template simplifies the use of JDBC, improves software development efficiency, makes the software easier to maintain and extend.

\section{References}

[1] H. Du, "Practical Application of Logistics Theoretical System in Large-scale Sports Events," Logistics Technology, vol. 32, no. 3, pp. 183-185, 2013.

[2] H. X. Ma, "Study on Assessment of Sports Event Logistics Service Capacity," Logistics Technology, vol. 31, no. 7, pp. 240-243, 2012.

[3] W. Wen, "Research on Evaluation and selection of large sports event logistics and its third party logistics service provider," Master's Degree of Beijing Sport University, 2008.

[4] X. F. Sun, L. Zhen, H. Y. Lv, "Research and design of sports logistics warehouse management information system," Logistics Technology, vol. 32, no. 6, pp. 268-269, 2013.

[5] Baidu Encyclopedia, "User layer," http://hanyu.iciba.com/wiki/64525.shtml, 2017-10-20.

[6] J. K. Wang, M. Li, "Design and implementation of front and back of travel strategy website based on Spring MVC architecture," Computer knowledge and technology, vol. 11, no. 8, pp. 268-269, 2015. 
[7] G. Q. Zhang, Y. Zhang, "Athlete shape index management system Spring JDBC data access," Techniques of Automation and Applications, vol. 36, no. 1, pp. 59-62, 2017. 